\title{
O INTELLECTU IN HABITUDE ALEXANDRE DE AFRODÍSIA
}

\author{
Evanildo Costeski \\ Universidade Federal do Ceará
}

\begin{abstract}
There is no doubt that Alexander of Afrodisias addressed issues related to the Intellectu in habitu in texts De Anima and De Intellectu. In the former, the Intellectu in habitu is presented as a mere recipient of concepts gathered by the potential intellect. In this way, the Intellectu in habitu is unable to perform abstract thinking. In the latter, the Intellectu in habitu is presented as a fully developed faculty capable of abstract thinking. This ability is given by the third intellect, called divine intellect. This article favors the interpretation proposed by De Intellectu. It is apposite to say that the Intellectu in habitu is capable of thinking because it, on the one hand, receives, the content provided by the potential intellect, and, on the other hand, receives the forms of intelligibility provided the divine intellect.
\end{abstract}

Keywords: Alexander of Afrodisias, potential intellect, intellectu in habitu, divine intellect, abstract.

Resumo: Alexandre de Afrodísia tratou claramente do Intellectu in habitu no De Anima e no De Intellectu. No De Anima, o intelecto em habitus é somente um depósito de conceitos latentes reunidos pelo intelecto potencial e, por isso, não cabe a ele a função de pensar ou abstrair. Já no De Intellectu, o Intellectu in habitu é considerado como uma faculdade plenamente desenvolvida, capaz de abstrair. Essa capacidade é dada pelo terceiro intelecto, chamado de Intelecto que "vem de fora" ou intelecto divino. Este artigo é favorável à interpretação do De Intellectu. Ele se apóia no fato de que o Intellectu in habitu é capaz de pensar porque recebe, por um lado, o conteúdo material dado pelo intelecto material ou potencial e, por outro lado, as formas inteligíveis dadas pelo intelecto divino.

Palavras Chaves: Alexandre de Afrodísia, intelecto potencial, intellectu in habitu, intelecto divino, abstrair. 
Alexandre de Afrodísia ${ }^{1}$ tratou claramente da héxis intelectual em dois textos de sua psicologia que chegaram até nós: o De Anima e o De Intellectu. Nesses textos, Alexandre fala da existência de três intelectos no homem: o intelecto material (nous hylikós), o intelecto em habitus (nous en héxei) e o intelecto "que vem de fora" (nous th rathen). ${ }^{2}$ Infelizmente, as notáveis divergências a respeito da noética do De Anima com a do De Intellectu, bem como a própria questão da autenticidade ou não do $D e$ Intellectu entre os comentadores atuais de Alexandre, dificultaram e dificultam até hoje qualquer interpretação coerente e definitiva da noética alexandrina. ${ }^{3}$ Não obstante, apesar das divergências latentes entre as duas obras, tentaremos compreender, tanto segundo o De Anima, como segundo o

${ }^{1}$ Pouco se sabe da vida de Alexandre. Parece que teve uma cátedra de filosofia em Atenas entre $198 \mathrm{e}$ 211 d.C., sob o domínio do imperador Septímio Severo, conforme informa G. REALE (1994, p. 34) e 0 próprio Alexandre no início do seu De Fato $(1984$, p. 6).

2 Sobre as três espécies de intelecto de Alexandre, cf. G. REALE (1994, p. 38-41).

${ }^{3}$ A autenticidade do De Intellectu foi colocada em dúvida na metade do século XX por P. MORAUX. Segundo MORAUX, embora existam várias teses idênticas entre os tratados do De Anima e o do De Intellectu, existem, ainda, notáveis divergências inexplicáveis entre as duas obras. Essas divergências têm sua raiz justamente na concepção do intellectu in habitu: "Memória intelectual enriquecida com species impressae segundo o de Anima, o nous en héxei torna-se, no de Intellectu, um estado de inteligência capaz de abstrair e de apreender por si mesmo as formas inteligíveis" (MORAUX, 1942, p. 133). Mais adiante, depois de comparar o conteúdo dos dois tratados, MORAUX pergunta se um dos dois constitui, em relação ao outro, um progresso na pesquisa filosófica. Segundo MORAUX, essa comparação não é possível, pois não existe nenhuma semelhança entre os dois tratados: "O de Anima não aparece como o desenvolvimento do de Intellectu e a recíproca é igualmente verdadeira" (id., ibid., p. 135). Como conclusão, MORAUX afirma que o De Intellectu retoma e deforma, involuntariamente, as principais idéias do De Anima. No final das contas, não dá para saber se o De Intellectu é um "plágio" ou um simples "trabalho escolar" (id. ibid., p. 142). Totalmente outra é a posição de BAZÁN. Para ele, o de Intellectu, "longe de se opor 'puramente e simplesmente' ao De anima, traz-lhe correções e complementos importantes que permitem melhor compreender 0 ato de conhecer na noética de Alexandre" (BAZÁN, 1973, p. 477). Por fim, conclui BAZÁN, contrapondo-se diretamente à tese de MORAUX: "O De intellectu não nos parece uma 'deformação involuntária' nem um simples 'trabalho escolar'; ao contrário, parece-nos que várias teses fundamentais do alexandrismo são aprofundadas e aparecem no De Intellectu com uma grande coerência" (id., ibid., p. 478). Já P. ACCATINO e P. DONINI, tradutores do De Anima para o italiano, afirmam que, no caso de existir um progresso entre as duas obras, a teoria mais madura e meditada é seguramente a exposta pelo De Anima (in: "Introduzione", ALEXANDRE, 1996, p. XXX). Ora, qualquer que seja a posição a respeito da autenticidade do De Intellectu, não podemos ignorar, como observa BAZÁN, que o pequeno tratado De Intellectu foi, entre os escritos de Alexandre, o que mais exerceu influência na Idade Média, graças a uma tradução árabolatina feita por Geraldo de Cremona a partir da versão greco-árabe de Ishad Bem Honein. Como lembra BAZÁN, para os escolásticos do século XIII, o De Intellectu era o único testemunho do pensamento autêntico de Alexandre (BAZÁN, 1973, p. 468). 
De Intellectu, em que sentido o intellectu in habitu (nous en héxei) pode pensar e abstrair.

\section{A função abstrativa acidental do intellectu in habitu no De Anima}

Segundo a tese de P. Moraux, a função de pensar ou de abstrair no De Anima de Alexandre não pertence, originariamente, ao intelecto in habitu nem ao intelecto "que vem de fora" (nous th rathen) mas, fundamentalmente, ao intelecto material (nous hylikós) ou potencial (nous $d$ namei). Ora, isto representa uma novidade em relação a Aristóteles. Para este, quem pode pensar é somente o intelecto agente (nous poietikós) (De Anima, III, 5). Ademais, enquanto para Aristóteles o intelecto agente e o intelecto paciente, isto é, o elemento agente e o passivo encontram-se "no interior da alma" (en té psyché) (id., ibid., III, 5, 430a 13) e, portanto, pertencem ao homem, para Alexandre, somente o intelecto potencial é originário do homem, haja vista que o intelecto agente, chamado por Alexandre de intelecto que "vem de fora" (nous th rathen) é transcendente (MORAUX, 1942, p. 88) e, como tal, identifica-se, como observa Eric Weil, com o primeiro motor aristotélico (1991, p. 98, nota 27). Por isso, quando se trata de pensar ou abstrair, o intelecto agente é, no De Anima de Alexandre, segundo a interpretação de Moraux, um mero coadjuvante (MORAUX, 1942, p. 87). ${ }^{4}$

Mas se a abstração é obra do intelecto material, como fica, então, o intellectu in habitu? $\mathrm{Na}$ verdade, segundo Moraux, a natureza e a função do intelecto in habitu não são claras no De Anima. Aliás, é justamente essa obscuridade do intelecto in habitu que leva Moraux a perguntar se esse habitus é por si mesmo uma faculdade própria independente ou, simplesmente, uma causa instrumental necessária à faculdade natural de abstração do intelecto material. A esse respeito, Moraux se apóia nas próprias palavras de Alexandre para concluir que o intelecto in habitu é somente "um depósito de conceitos latentes” (MORAUX, 1942, p. 68-69) reunidos pelo intelecto potencial, sem possuir nenhuma capacidade abstrativa independente. É verdade, que "o nous en héxei pode, também, conduzir essas species ao estado de inteligibilidade atual” (id., ibid., p. 78), todavia, isso não

\footnotetext{
4 Para BAZÁN, esta posição de MORAUX não corresponde inteiramente à verdade, porquanto o intelecto agente permanece um elemento necessário no processo de conhecimento de Alexandre, porém, não como princípio de abstração, mas como fonte de inteligibilidade (BAZÁN, 1973, p. 471, nota 12).
} 
significa, necessariamente, um poder de abstração originário da héxis, mas somente um retorno acidental sobre si mesma, mais exatamente, sobre os conceitos previamente depositados na memória intelectual pela inteligência sensível ou material.

\section{A função abstrativa essencial do intellectu in habitu no De intellectu}

Totalmente outra é a função do intellectu in habitu no De Intellectu (peri nou). Nesta obra, o intelecto in habitu é análogo ao dos homens que possuem o habitus de determinadas profissões e, por isso, podem facilmente realizar os trabalhos próprios dessas profissões. Assim, o nous en héxei não é nada mais nada menos que o intelecto material potencializado com a capacidade de pensar e de agir, o qual se encontra apenas nos homens mais completos, isto é, naqueles que têm a capacidade de pensar os inteligíveis (ALEXANDRE, De Intellectu, 107, 20-29, in: MORAUX, 1942, p. 186).

Desse modo, diferentemente do De Anima, onde o intellectu in habitu era apenas uma reserva de species impressae dada pelos sentidos e conservada pela memória, o nous en héxei é, no De Intellectu, uma faculdade apta a abstrair. Com isso, o intelecto potencial (nous $d$ namei) ou material (nous hylikós), que no De Anima era uma faculdade completamente desenvolvida, torna-se, no De Intellectu, uma faculdade que, simplesmente, não pensa, embora permaneça em potência de pensar todas as coisas: "ele não é nenhuma das realidades em ato, mas poderá se tornar todas" (ALEXANDRE, De Intellectu, 106, 26-27, in: MORAUX, 1942, p. 185.). Portanto, no De Intellectu, quem pensa não é mais o nous hylikós, mas o nous en héxei, haja vista que a capacidade de pensar e de abstrair é, no De Intellectu, uma função própria do habitus noético.

Mas como a héxis adquire a capacidade de abstrair e pensar? Para o De Intellectu, a capacidade de abstrair da héxis é dada pelo terceiro intelecto, isto é, o intelecto agente, chamado por Alexandre de intelecto que "vem de fora" (nous th rathen). Com efeito, segundo Alexandre, é graças à ação do intelecto agente, que Aristóteles compara com a função da luz (De Anima, III, 5, 430a 17), que o intelecto material adquire o habitus noético (ALEXANDRE, De Intellectu, 107, 30-35, in: MORAUX, 1942, p. 187). Mas, atenção: é somente como Causa Primeira Formal que o intelecto divino comunica a sua inteligibilidade ao homem. Ele não é causa direta da "inteligibilidade atual" do intelecto humano: "É apenas de uma maneira 
indireta que 'o intelecto agente é causa do habitus do intelecto material'." (MORAUX, 1942, p. 93). Como veremos em seguida, o intelecto agente só é causa primeira quando pensado pelo intellectu in habitu do indivíduo.

Tanto no De Anima, como no De Intellectu, o intelecto agente é inteligível em ato por natureza. Desse modo, é óbvio que o intelecto divino em ato é separado da matéria e, como tal, não depende de nosso pensamento para possuir a qüididade de intelecto. Ele "vem de fora" (nous th rathen), é exterior ao nosso pensamento e, por isso, existe como Forma Pura antes de ser pensado e, naturalmente, quando é pensado pelo intelecto humano (ALEXANDRE, De Intellectu, 109, 3-4, in: MORAUX, 1942, p. 188).

Mas se o intelecto agente "vem de fora", como pode ser fonte de inteligibilidade para o intelecto em potência? Como já sabemos, o intelecto agente não exerce uma "causalidade abstrativa": esta permanece sendo, na interpretação de Moraux, uma função própria do nous hylikós. Porém, como observa Bazán, o intelecto material ou potencial abstrai quando alcança o habitus de pensar, fornecido pelo intelecto agente (BAZÁN, 1973, p. 480). Desse modo, ao contrário do que pensa Moraux, é evidente que o nous en héxei não pode ser, simplesmente, um depósito de "species impressae", mas, realmente, uma faculdade apta a abstrair, originada do intelecto agente.

Como sabemos, a ação do intelecto agente sob o intelecto material não pode ser direta e imediata. $\mathrm{O}$ nous hylikós precisa se adequar às formas inteligíveis do intelecto divino em ato, por isso, deve existir uma relação de subordinação (anaphorá) entre o intelecto humano material e o intelecto agente divino. ${ }^{5}$ É pensando e imitando a atualidade divina do intelecto agente que o intelecto humano se torna capaz de abstrair as formas da matéria, tornando-a, assim, inteligível (ALEXANDRE, De Intellectu, 108, 1922, in: MOURAUX, 1942, p. 187). Com isso, fica claro que o intelecto material mantém com o intelecto divino em ato "uma relação de imitação (mimeisthai) que se completa precisamente pela separação (Chorizein) (as formas são tornadas imateriais como o inteligível em ato)” (BAZÁN, 1973, p. 482). É através dessa relação de subordinação (anaphorá) que o nous th rathen fornece, indiretamente, ao intelecto potencial, o habitus noético. O

\footnotetext{
5 Como observa MORAUX: "Em Alexandre os termos anaphorá e anaphérein (...) designam uma relação do inferior ao superior, qual seja a relação do meio ao fim, aquela da espécie ao gênero, ou simplesmente aquela de uma coisa possuindo tal qualidade a uma outra coisa que possui esta qualidade em um grau mais eminente" (1942, p. 130).
} 
que significa isso? Por um lado, que a abstração é, inicialmente, uma atividade do intelecto humano material (nous hylikós) e, por outro lado, que a causa última dessa abstração não pertence ao intelecto potencial, mas ao intelecto que "vem de fora" (nous th rathen). Qual seria, então, a originalidade da função abstrativa do intellectu in habitu?

\section{0 intelecto agente como causa formal da abstração do intellectu in habitu.}

Como vimos, no De Anima, o intellectu in habitu é, segundo a interpretação de Moraux, apenas um receptáculo das impressões dos objetos externos obtidas pelos sentidos, na medida em que a função de abstrair pertence, originariamente, ao intelecto material-potencial. Já no De Intellectu, ao contrário, o intellectu in habitu se torna uma faculdade apta a abstrair, enquanto o intelecto potencial permanece meramente passivo. Como resolver esta contradição?

Diferentemente de Moraux, Bazán não consegue entender como um intelecto potencial pode abstrair por si mesmo, sem já possuir uma certa atualidade (BAZÁN, 1973, p. 482). No De Intellectu, a atividade abstrativa do intellectu in habitu tem como origem o nous th rathen que, como tal, "vem de fora" e funda a inteligibilidade de todas as outras formas, "as quais serão, assim, abstratas, por uma realidade que já possui uma primeira atualidade” (loc. cit.). Segundo nossa interpretação, essa é a verdadeira função do nous th rathen de Alexandre de Afrodísia, chamado por P. Thillet, no sentido dado por Avicena, de intelecto "doador das formas", ou no caso específico de Alexandre, de intelecto "doador da inteligibilidade das formas" (THILLET, 1981, p. 21-22). A partir disso, é fácil perceber que o nous en héxei não pode ser apenas um receptáculo de "species impressae" fornecida pelos sentidos, mas um verdadeiro "receptáculo de inteligibilidade".

Bem entendido, este "receptáculo de inteligibilidade" não possui nenhum conteúdo dado diretamente pelo intelecto agente, mas somente a "forma da inteligibilidade" originada da relação de subordinação (anaphorá) entre o intelecto potencial e o intelecto em ato. Desse modo, o intellectu in habitu funcionaria, segundo nossa compreensão, como uma espécie de mediação entre o intelecto agente e o intelecto material-potencial dos sentidos. Ele é capaz de abstrair e pensar a forma da matéria sensível 
justamente porque recebe do intelecto agente divino a forma de pensar, da mesma maneira que recebe a matéria do intelecto material-potencial.

Entretanto, embora importante, esta atividade abstrativa do intellectu in habitu permanece, essencialmente, passiva, na medida em que o intelecto em habitus é apenas um depósito de specie impressae do intelecto material e um "receptáculo de inteligibilidade" dado pelo intelecto agente. Todavia, se é verdade que a matéria é dada pelos sentidos e a forma pelo intelecto divino em ato, a decisão de pensar, isto é, a decisão de retornar sobre si mesmo e reunir em-si e para-si o em-si da matéria e o para-si da forma inteligível é própria do intellectu in habitu. Com efeito, o nous en héxei é formado no homem "desde que pense", isto é, desde que adquire capacidade de pensar e apreender, por si mesmo, as formas inteligíveis (ALEXANDRE, De Intellectu, 107, 21-22, in: MORAUX, 1942, p. 186). Por isso, é óbvio que ele não é somente passivo, mas, também, ativo: é passivo enquanto recebe a matéria do intelecto potencial e a forma do intelecto agente; e ativo enquanto decide pensar por si mesmo as informações recebidas pelos sentidos, segundo a forma do pensar do intelecto divino. É verdade que a atividade do intellectu in habitu depende da forma metafísica do intelecto divino e do conteúdo fornecido pelos sentidos; porém, é verdade, ainda, que a Forma só existe para o homem enquanto pensada pelo intelecto humano.

Segundo o Exegeta, o intelecto humano, ao pensar o intelecto divino, tende a se identificar com ele, conquanto um dos acidentes do intelecto em héxis é, na medida em que pensa, tornar-se o objeto pensado (ALEXANDRE, De Anima, 86, 20-23; 1996, p. 84). Desse modo, o intelecto humano adquire a Forma de pensar na medida em que participa da ação reflexiva do intelecto em ato, até o ponto de a própria theoría divina tornar-se natural ou um simples estilo de vida para o indivíduo (WEIL, 1992, p. 151).

\section{Considerações finais}

O habitus noético adquiriu, em Alexandre de Afrodísia, uma potencialidade de abstração até então inédita dentro do aristotelismo. Essa posição de Alexandre exerceria uma influência imensa em toda a tradição aristotélico-árabe e, indiretamente, sobre o pensamento medieval ocidental. Porém, devido a sua originalidade, tanto a interpretação árabe quanto a cristã medieval teriam sérias dificuldades para compreender a autonomia do intellectu in habitu de Alexandre (GILSON, 1929). Santo Tomás, por 
exemplo, ao refutar a unidade do intelecto agente divino defendida pelos comentadores árabes, parte do princípio de que existem no indivíduo dois tipos de intelecto, a saber, o intelecto possível e o intelecto agente. Essa posição contrasta com Alexandre, para quem existe um terceiro intelecto, o habitus noético, entendido como potencialização absoluta do intelecto possível.

Para a constituição do intelecto em habitus é necessário, por um lado, a matéria oferecida pelos sentidos e, por outro lado, a forma universal dada pelo intelecto divino. O esforço humano para compreender segundo a Forma (divina) criaria, através da potencialização do intelecto possível-material, o intelecto em habitus, ou seja, um intelecto humano capaz de pensar absolutamente a matéria oferecida pelos sentidos segundo a Forma divina.

Desse modo, a existência de um intelecto em habitus autônomo e independente no indivíduo depende da função do intelelecto agente aristotélico. Enquanto, para Alexandre, o intelecto agente ou divino se identifica com o nous th rathen ou intelecto que "vem de fora", para Santo Tomás, o intelecto agente não é separado, mas sim presente em cada indivíduo particular.

Em um primeiro momento, a identificação do nous th rathen de Alexandre com o intelecto agente aristotélico parece impossibilitar uma concepção autônoma e independente do pensar humano. Nesse sentido, a posição tomista em relação à individualidade dos intelectos agente e possível e, conseqüentemente, a necessidade dos sentidos para o conhecimento, significa uma verdadeira revolução na teoria do conhecimento, em confronto à tradição aristotélico-áraba, a qual defende que o pensamento não depende do corpo, mas de um único intelecto agente divino (WEIL, 1985, p. 15). O problema é que a posição tomista não é suficientemente radical. Santo Tomás deveria, além de afirmar a necessidade dos sentidos para o conhecimento, afirmar, também, a primazia antropológica do homem sobre o intelecto, coisa que ele não faz. Para isso, teria que admitir a existência no homem, além do intelecto possível e do intelecto agente, do intelecto em habitus, entendido como "possessão" dinâmica e absoluta, tanto das informações recebidas dos sentidos, como da Forma inteligível dada pelo intelecto agente. Em nossa opinião, o "esquecimento" tomista do intelecto em habitus de Alexandre ocasionou sérios danos ao pensamento filosófico, principalmente, na constituição de uma autêntica antropologia noética. Sem um habitus noético autônomo fundamentado na própria atitude humana, o indivíduo 
fica coxo, incompleto e imperfeito, incapaz de oferecer um sentido antropológico ao sistema filosófico e, conseqüentemente, de agir de forma sensata na história. Somente enquanto possuidor de um habitus noético autônomo e dinâmico, tal como defendido por Alexandre, o indivíduo poderia, realmente, determinar-se e se compreender como livre e autônomo no mundo. 


\section{Referências}

ACCATTINO, P.; DONINI, P. Introduzione. In: ALEXANDRE DE AFRODÍSIA. L’Anima. Tradução italiana, introdução e comentário de P. Accatino e P. Donini. Roma: Laterza, 1996.

ALEXANDRE DE AFRODÍSIA. De Intellectu. Tradução francesa de P. Moraux. In: MORAUX, P. Alexandre d'Aphrodise. Exégète de la Noétique d'Aristote. Paris: Librairie E. Droz, p. 185-194, 1942. L’Anima. Tradução italiana, introdução e comentário de P. Accatino e P. Donini. Roma: Laterza, 1996.

Traité du Destin. Tradução francesa de P. Thillet (ed. bilíngüe). Paris: Les Belles Lettres, 1984.

Praeter commentaria scripta minora: de Anima Liber cum Mantissa (ed. I. Bruns). Berlim: Reimer, 1887.

ARISTÓTELES. Anima. Texto grego com tradução italiana de G. Movia. Milão: Rusconi, 1996.

BAZÁN, B. C. L'authenticité du De Intellectu attribué à Alexandre d'Aphrodise. In: Revue Philosophique de Louvain, v. 71, p. 468-487, 1973.

GILSON, E. Les sources gréco-arabes de l'augustinisme avicennisant. In: Archives d'histoire doctrinale et littéraire, v. 4, p. 5-149, 1929.

MORAUX, P. Alexandre d'Aphrodise. Exégète de la Noétique d'Aristote. Paris: Librairie E. Droz, 1942.

REALE, G. História da filosofia antiga. Tradução portuguesa de Henrique C. de Lima e Marcelo Perine. São Paulo: Loyola, v. 4, 1994.

THILLET, P. Matérialisme et théorie de l'âme et de l'intellect chez Alexande d'Aphrodise. In: Revue philosophique de la France et de l'etranger, v. 171, p. 5-24, 1981.

WEIL, E. La philosophie di Pietro Pomponazzi. Pic de la Mirandole et la critique de l'astrologie. Paris: Vrin, 1985.

. Philosophie morale. Paris: Vrin, 1992.

. Quelques remarques sur le sens et l'intention de la Métaphysique aristotélicienne. In: Essais et conférences. Paris: Vrin, v. 1, p. 81-105, 1991.

E-mail: evanildoc@uol.com.br

Recebido em: 08/2009

Aprovado em: 11/2009 